\title{
Anesthesiology resident selection: identifying mandate and selection criteria in Saskatchewan
}

\author{
Mateen Raazi, MD, FRCPC $\cdot$ Jennifer O'Brien, PhD (i) - Derrick Williams, MD, \\ FRCPC
}

Received: 11 January 2019/Revised: 15 January 2019/Accepted: 15 January 2019/Published online: 6 February 2019

(C) Canadian Anesthesiologists' Society 2019

\section{To the Editor,}

Residency positions in Canada are filled using the Canadian Resident Matching Service (CaRMS) in an algorithm that matches applicants to residency programs according to rank order lists dually generated by applicants and residency programs. Applicants provide detailed curricula vitae, lists of electives, personal letters, reference letters, transcripts, and medical student performance records (i.e., "Dean's letters"). Residency programs review applicant files, shortlist applicants, and carry out interviews.

While there are credible indicators for success in medical school, evidence for predictors of success in postgraduate specialty training is limited and conflicting. ${ }^{1-3}$ The strongest evidence supports the use of academic records, multiple mini-interviews, situational judgement tests, and tests of clinical problem solving as selection tools. ${ }^{3}$ Conflicting or varied evidence exists for aptitude tests, personal statements, some personality traits, and traditional interviews. ${ }^{1}$ Limited or weak evidence exists for the effectiveness of references and emotional intelligence on performance. ${ }^{1,3}$ Furthermore, one study found that orthopedic surgeons ranked postgraduate candidates more favorably when they shared personality traits with the

Electronic supplementary material The online version of this article (https://doi.org/10.1007/s12630-019-01304-z) contains supplementary material, which is available to authorized users.

M. Raazi, MD, FRCPC · J. O’Brien, PhD ( $₫)$.

D. Williams, MD, FRCPC

Department of Anesthesiology, Perioperative Medicine and Pain

Management, University of Saskatchewan, Saskatoon, SK,

Canada

e-mail: Jennifer.OBrien@usask.ca candidate, highlighting the potential for bias in the selection process. ${ }^{4}$

In an effort to reduce the variability of subjective measures (including bias) in local resident selection, we surveyed staff anesthesiologists and residents in our Department to determine their perceived mandate for resident selection and which criteria they identified as most important for resident selection. The University of Saskatchewan Behavioural Research Ethics Board deemed this study exempt from ethical review as a program evaluation (May 2014). We invited all 138 residents and staff anesthesiologists in the Department of Anesthesiology at the University of Saskatchewan's programs in Saskatoon, Regina, and Prince Albert to participate in this prospective online survey (eAppendix, available as Electronic Supplementary Material). Potential participants were informed that their responses would be used for research purposes and that survey completion implied consent. The survey tool was developed according to established guidelines using literature review, review of the current evaluation practice, and focused discussion with the survey team. ${ }^{5}$ Following pre-testing and pilot testing, the survey was distributed via email using the FluidSurveys tool, and anonymous data were exported into Microsoft Excel for statistical analysis.

One hundred residents and staff responded to the survey (100/138, 72\%). Respondents were primarily male (68/100, $68 \%$ ), Fellows of the Royal College of Physicians of Canada $(70 / 100,70 \%)$, had participated in the CaRMS process within the past five years $(60 / 100,60 \%)$, and were located within Saskatoon $(74 / 100,74 \%)$. The primary reported mandates of resident selection were to select applicants: 1) to be successful in anesthesiology (94/100, $94 \%) ; 2)$ to serve Canadian patients $(52 / 100,52 \%), 3)$ to serve Saskatchewan patients $(34 / 100,34 \%) ; 4)$ to serve 
Western Canadian patients $(15 / 100,15 \%)$; 5) who are representative of the population they will serve $(19 / 100$, $19 \%)$; 6) to fill subspecialty areas of need $(18 / 100,18 \%)$; and 7) to serve underserved populations $(16 / 100,16 \%)$. Academic and non-academic criteria and individual qualities reported to be most important for resident selection are outlined in the Supplementary Table.

Identified negative criteria (i.e., "red flags") included attitude problems identified through reference letters or interview (95/100, 95\%), dishonesty/plagiarism (94/100, 94\%), and disciplinary action during medical school (93/ $100,93 \%)$. Respondents assigned the greatest proportion of the overall score to the interview, followed closely by the file review score. Ninety-one $(91 \%)$ respondents indicated they would assign a portion of the total score to a subjective "Star Quality."

Our survey assessed the perceived mandate of anesthesiology resident selection in Saskatchewan and prioritized the factors that were perceived to be the most important and most predictive for resident success. The next steps to improve the local resident selection processes include modifying the current scoring algorithm according to evidence-based metrics for resident selection and to assessing the validity of subjective qualities in the scoring algorithm.

Conflicts of interest None declared.
Editorial responsibility This submission was handled by Dr. Hilary P. Grocott, Editor-in-Chief, Canadian Journal of Anesthesia.

\section{References}

1. Patterson F, Roberts $C$, Hanson MD, et al. 2018 Ottawa consensus statement: selection and recruitment to the healthcare professions. Med Teach 2018; DOI: https://doi.org/10.1080/0142159x.2018. 1498589.

2. Prideaux D, Roberts $C$, Eva $K$, et al. Assessment for selection for the healthcare professions and specialty training: consensus statement and recommendations from the Ottawa 2010 Conference. Med Teach 2011; 33: 215-23.

3. Roberts $C$, Khanna P, Rigby L, et al. Utility of selection methods for specialist medical training: a BEME (best evidence medical education) systematic review: BEME guide no. 45. Med Teach 2018; 40: 3-19.

4. Quintero AJ, Segal LS, King TS, Black KP. The personal interview: assessing the potential for personality similarity to bias the selection of orthopaedic residents. Acad Med 2009; 84: 1364-72.

5. Burns $K$, Duffett $M$, Kho ME, et al. A guide for the design and conduct of self-administered surveys of clinicians. CMAJ 2008; 179: $245-52$.

Publisher's Note Springer Nature remains neutral with regard to jurisdictional claims in published maps and institutional affiliations. 